\title{
PERANCANGAN ILUSTRASI CERITA RAKYAT ANGGUN NAN TONGGA MELALUI MEDIA E-BOOK
}

\author{
Assaidatul Husna ${ }^{1 *}$, Yoni Sudiani ${ }^{2^{*}}$ Olvyanda Ariesta ${ }^{3^{*}}$ \\ Program Studi Desain Komunikasi Visual Fakultas Seni Rupa dan Desain \\ Institut Seni Indonesia Padangpanjang \\ Jl. Bahder Johan, Guguak Malintang, Padangpanjang, Kota Padangpanjang, 27126. \\ Sumatera Barat. Indonesia \\ Email: assaidatulhusna@gmail.com
}

\begin{abstract}
Abstrak
Perancangan ini bertujuan untuk menyajikan kembali cerita rakyat Anggun Nan Tongga sehingga dapat memperkenalkan dan meningkatkan daya tarik remaja terhadap cerita rakyat Indonesia tersebut. Anggun Nan Tongga merupakan seorang pemuda yang berupaya menjaga harga diri keluarganya, namun dalam upayanya tersebut Anggun Nan Tongga hehilangan kepercayaan dari kekasihnya Putri Gondan Gandoriah. Proses perancangan diawali dengan pengumpulan data melalui observasi, studi pustaka, wawancara, dan kuesioner selanjutnya menentukan konsep visual, perancangan karakter, sinopsis, premis, plot, storyline, storyboard, pewarnaan digital, me-layout dan pengaplikasian. Hasil yang dicapai adalah menghadirkan ilustrasi dalam bentuk karya visual ilustrasi dengan target audiens remaja berusia 13-18 tahun. Dengan adanya e-book ilustrasi Anggun Nan Tongga diharapkan cerita rakyat ini mudah dijangkau oleh remaja yang saat ini dekat dengan penggunaan internet. Serta elemen-elemen grafis seperti ilustrasi, layout, warna, tipografi/teks menjadi unsur penting dalam merancang ilustrasi cerita rakyat ini sehingga dapat menarik perhatian remaja.
\end{abstract}

Kata Kunci: anggun dan tongga, e-book, ilustrasi.

\begin{abstract}
This design aims to present back Anggun Nan Tongga folklore so that it can introduce and enhance the appeal of adolescent to the story of the people of Indonesia. Anggun Nan Tongga is a young man who seeks to maintain the dignity of his family, but in the effort Anggun Nan Tongga losing the trust of Princess Gondan Gandoriah lover. The design process begins with data collection through observation, interview, literature study, and further questionnaire determines visual concepts, character design, synopsis, premise, plot, storyline, storyboard, digital coloring, layout and application. The result is illustration in visual illustration with target audience of 13-18 year old teenager. With the e-book illustration Anggun Nan Tongga expected this folklore easy to reach by adolescents who are currently close to the use of the internet. As well as graphic elements such like illustrations, layouts, colors, typography / text become an important element in designing this folklore illustration so as to attract the attention of adolescents.
\end{abstract}

Keywords: anggun dan tongga, e-book, ilustrasi.

\section{PENDAHULUAN}

Sumatera Barat merupakan salah satu provinsi di Indonesia yang terletak di pulau Sumatera. Sumatera Barat kaya akan pesona alam seperti pantai, danau, sungai, dan gunung menjadikannya destinasi wisata pilihan bagi turis. Karena alamnya inilah yang menumbuhkan keberagaman seni budaya seperti pakaian, arsitektur, tari, kuliner, bahasa, dan cerita rakyatnya yang memberi daya gugah masyarakat untuk mengunjungi provinsi ini.

Pariaman sebagai salah satu daerah di Sumatera Barat yang berada dipesisir pantai Sumatera, berbatasan langsung dengan Samudera Indonesia. Pariaman dengan sejarahnya yaitu Kota Pariaman, Kabupaten
Padang Pariaman, Tiku, dan sebagian wilayah di Kota Padang dahulunya merupakan tujuan perdagangan saudagar Eropa, India, Persia, dan Gujarat. Sehingga menyebabkan masyarakatnya menyerap seni budaya mereka dan terjadinya akulturasi budaya seperti pada drama, prosa, tari, musik, dan perayaan.

Salah satu nilai budaya Pariaman adalah cerita rakyat. Cerita rakyat merupakan sastra prosa yang dituturkan, bukan secara tertulis. Kini cerita rakyat bertransformasi dari bahasa lisan ke bahasa tulis maupun ke dalam wahana audiovisual disertai sejumlah perubahan estetika (citarasa). Cerita rakyat memiliki nilai-nilai moral, norma-norma yang mendasar dari budayanya dan lebih 


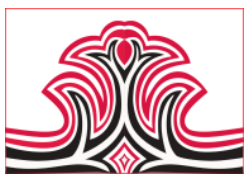

mempermasalahkan martabat manusia yang egaliter (Navis, 1983:51-52).

Anggun Nan Tongga merupakan salah satu cerita rakyat dari daerah Pariaman. Cerita rakyat ini menceritakan seorang pemuda yang bernama Anggun Nan Tongga yang berusaha menjaga harga diri keluarganya. Dalam cerita ini juga menceritakan kisah cinta Anggun Nan Tongga dengan Putri Gondan Gandoriah yang tidak berjodoh di dunia namun berjodoh di akhirat. Cerita rakyat ini merupakan cerita yang banyak memuat nilai-nilai moral orang Pariaman yang terkenal sebagai orang yang kuat mempertahankan harga diri. Dalam karya sastra ini juga menunjukkan bahwa masyarakat Pariaman memegang teguh filosofinya yaitu "Adat Basandi Syara', Syara' Basandi Kitabullah” (Setiap aktifitas hidup harus berdasarkan tuntunan dan syariat agama), dan banyak nilai moral lainnya yang terkandung dalam cerita rakyat Anggun Nan Tongga.

Menurut Asnul Nazar selaku Kepala Bidang Pemasaran dan Kerjasama Pariwisata Kota Pariaman, cerita rakyat Anggun Nan Tongga sudah semakin jarang diketahui masyarakat, kecuali oleh kalangan sesepuh masyarakat (http.indonesiakaya.com diakses 15/04/2016 16.23). Upaya dalam dokumentasi cerita rakyat Anggun Nan Tongga sudah dilakukan oleh beberapa penerbit di Sumatera Barat melalui text book namun belum ada media alternatif lain. Kurangnya ketertarikan masyarakat terhadap buku cerita rakyat yang berisikan tulisan, menyebabkan diperlukannya sebuah media komunikasi visual yang efektif dalam mendokumentasikan dan melestarikan cerita rakyat Anggun Nan Tongga ini.

Berdasarkan permasalahan di atas maka diperlukan sebuah upaya untuk menyajikan kembali cerita rakyat dalam bentuk yang lebih menarik dan mengikuti perkembangan zaman. Hal ini bertujuan agar masyarakat terutama generasi muda termotivasi membaca cerita rakyat tersebut. Salah satu upaya yang dapat dilakukan adalah menyajikan kembali buku teks ke dalam bahasa visual. Melalui Bahasa visual yang berbentuk ilustrasi ini masyarakat terutama generasi muda dapat tertarik dengan cerita rakyat Anggun Nan Tongga.

\section{KAJIAN TEORI}

\section{Ilustrasi}

Ilustrasi pada saat ini banyak digemari oleh generasi muda. Dikarenakan pada ilustrasi menyajikan bentuk dan warna-warna yang menarik bagi mereka. Generasi muda akan membaca buku setipis dua belas halaman
Gorga Jurnal Seni Rupa

Volume 08 Nomor 01 Januari-Juni 2019

p-ISSN: 2301-5942 | e-ISSN: 2580-2380

hingga kira-kira tiga puluh halaman asalkan memiliki tampilan yang bagus dan menarik.

Wojirsch (1995:35) berpendapat, ilustrasi merupakan gambaran pesan yang tak terbaca yang dapat menguraikan cerita, berupa gambar dan tulisan, yaitu bentuk grafis informasi yang memikat. Sehingga dapat menjelaskan makna yang terkandung didalam pesan tersembunyi.

Ilustrasi secara harafiah berarti gambar yang dipergunakan untuk menerangkan atau mengisi sesuatu (Kusrianto, 2009:110). Dalam perkembangannya, ilustrasi secara lebih lanjut ternyata tidak hanya berguna sebagai sarana pendukung cerita, tetapi dapat juga menghiasi ruang kosong.

Dalam buku Bacic Visual Concepts and Principles oleh Charles Wallsclhaeger dan Cynthia Busic Snyder, (1992) dijelaskan bahwa gambar dan warna adalah salah satu bentuk pola penyampaian pesan yang dapat berfungsi untuk mendramatisir, memperjelas, meningkatkan nilai visual, bahkan sampai mempengaruhi sikap audience.

Kesimpulan dari tiga teori mengenai ilustrasi diatas bahwa ilustrasi berfungsi sebagai pendukung, mendramatisir, memperjelas, menambah nilai estetis hingga mempengaruhi target audience sehingga tertarik terhadap karya.

Teknik ilustrasi komputer, membuat ilustrasi dengan bantuan komputer serta software pendukungnya. Teknik Digital Painting, teknik menggambar dengan tangan tetapi dibantu oleh bantuan komputer serta tablet pc/tablet pen. Digital painting memungkinkan terciptanya hasil karya yang mendekati foto asli atau juga mendekati hasil karya lukisan manual. Teknik Block, teknik Block adalah teknik menggunakan blokblok warna dekoratif (rata datar). Pewarnaan pada objek menggunakan tingkatan, tine, tone, dan shade. Dari keseluruhan penjelasan mengenai teknik ilustrasi komputer diatas, perancangan ilustrasi cerita rakyat Anggun Nan Tongga akan menggunakan teknik block dan digital painting yang tidak dominan. Penggabungan antara dua teknik ilustrasi tersebut akan menjadikan cerita rakyat Anggun Nan Tongga lebih menarik.

\section{Layout}

Layout bukan hanya sebatas menata letak materialmaterial (content) tetapi bagaimana mengorganisasikan ruang. Menurut Surianto Rustan, 


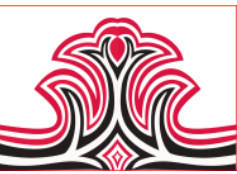

pada dasarnya layout dapat dijabarkan sebagai tata letak elemen-elemen desain terhadap suatu bidang dalam media tertentu untuk mendukung konsep/pesan yang dibawanya. Me-layout adalah salah satu proses/tahapan kerja dalam desain. Dapat dikatakan bahwa desain merupakan arsiteknya, sedangkan layout pekerjanya (Rustan, 2009:0).

Sehingga menyusun layout merupakan pekerjaan yang sangat menentukan. Sebuah ide, copywrite, atau pun elemen-elemen yang bagus akan gagal bila disusun dan disajikan dengan layout yang kurang tepat (Kusrianto, 2009:307). Salah satunya seperti mempertimbangkan unsur yang akan memperoleh perhatian terlebih dahulu dari target audience, sehingga memberikan dampak yang diharapkan.

Sebuah karya desain yang baik dan menarik akan terus menggunakan layout yang sesuai. Maka itu harus memperhatikan prinsip-prinsip layout yaitu: a) Urutan (Sequence), dalam desain, tidak semua informasi bisa ditampilkan sama kuat karena dapat membuat pembaca kesulitan menangkap pesan. Sequence adalah mengurutkan informasi dari yang harus dibaca pertama sampai yang bisa dibaca setelah pesan utama. b) Penekanan (Emphasis), dalam desain, penekanan dapat diberikan terhadap informasi utama agar menjadi pusat perhatian. Penekanan dapat dilakukan dengan beberapa cara, diantaranya memberikan ukuran yang jauh lebih besar dibanding elemen lain, memberi warna yang kontras dengan latar belakang dan elemen lain, meletakkan elemen di posisi yang menarik perhatian, dan menggunakan bentuk/style yang berbeda dengan sekitarnya. c) Keseimbangan (Balance), pembagian berat yang merata pada suatu bidang layout. Pembagian berat bertujuan menghasilkan kesan seimbang dengan menggunakan elemen-elemen yang dibutuhkan dan meletakkannya pada tempat yang tepat. d) Kesatuan (Unity), Prinsip kesatuan adalah memadu-padankan semua elemen desain agar saling berkaitan dan tersusun dengan tepat (Rustan, 2009:74-86).

Karya Desain Komunikasi Visual memiliki begitu banyak elemen-elemen. Semua elemen ini bertujuan menyampaikan informasi dengan lengkap dan tepat, kenyamanan dalam membaca, kemudahan mencari informasi yang dibutuhkan, serta navigasi dan estetika. Elemen layout di bagi menjadi 3: a) Elemen Teks, elemen teks ini terdiri dari judul, deck, byline, bodytext, subjudul, pullquote, caption, callouts, kickers, initial caps, indent, lead line, spasi, header dan footer, running head, catatan kaki, nomor halaman, jumps, signature, nameplate, dan masthead.
Gorga Jurnal Seni Rupa

Volume 08 Nomor 01 Januari-Juni 2019

p-ISSN: 2301-5942 | e-ISSN: 2580-2380

b) Elemen Visual, elemen visual merupakan semua elemen bukan teks yang terdiri dari foto, artwork, infographics, garis, kotak, inzet, dan poin. c) Invisible element, elemen yang termasuk sebagai invisible elemet merupakan pondasi atau kerangka yang berfungsi sebagai acuan penempatan semua elemen layout seperti margin dan grid. (Rustan, 2009:27-72).

\section{3).Tipografi}

Teks merupakan salah satu elemen layout terpenting. Elemen teks memiliki peran penyampai pesan komunikasi yang dibutuhkan target audience. Membicarakan teks berarti membicarakan tipografi. Tipografi kini dimaknai sebagai segala disiplin yang berkenaan dengan huruf (Rustan, 2010:16). Kaitan tipografi pada layout yaitu memilih jenis huruf dan ukurannya termasuk jarak antar-huruf, kata, baris dan lebar paragraf.

Menurut Adi Kusrianto (2009:190) Tipografi didefinisikan sebagai suatu proses seni untuk menyusun bahan publikasi menggunakan huruf cetak. Oleh karena itu, "menyusun" meliputi merancang banyak huruf cetak hingga merangkainya dalam sebuah komposisi yang tepat untuk memperoleh suatu efek tampilan yang dikehendaki.

Sehingga dapat disimpulkan penggunaan tipografi yang sesuai dalam sebuah karya desain akan menyampaikan informasi dan pesan dengan baik, dapat dipahami dan memunculkan efek yang diinginkan.

\section{Warna}

Warna merupakan unsur visual yang terdapat pada sebuah karya desain. Menurut Adi Kusrianto (2009:31) "Warna merupakan unsur visual yang berkaitan dengan bahan yang mendukung keberadaannya ditentukan oleh jenis pigmennya. Warna akan menentukan kesan terhadap suatu karya.

Penggunaan warna dari sebuah karya desain biasanya disesuaikan dengan konsep karya desain tersebut. Seperti sebuah karya yang mengusung konsep budaya akan memperhatikan tekstil, bendera, seni dari daerah dimana budaya tersebut berasal dan karya dengan konsep alam akan mengambil warna dari alam seperti bumi, langit dan laut (Krause, 2002: 205). Pewarnaan yang baik akan mampu menarik minat manusia pada suatu karya. Karena warna merupakan unsur yang sangat penting untuk membuat kesan atau mood.

Penggunaan warna pada dewasa ini tidak sebagaimana penggunaan seperti masa lampau ketika masyarakat 


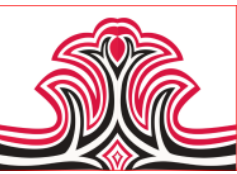

masih mempertimbangkan nilai simbiolis. Penggunaan warna untuk keperluan praktis pada dewasa ini lebih menitikberatkan kepada nilai-nilai psikologis, baik psikologis individu maupun psikologis massa. Pertimbangan psikologis massa dapat dispesifikasikan lagi menjadi tipe masyarakat yang bagaimana, dan psikologis individu dapat diterangkan melalui kepribadian individual dimana selera termasuk didalamnya (Darmaprawira, 2002: 103-104).

Warna-warna utama yang merupakan pantulan kebudayaan Minangkabau menurut (Darmaprawira, 2002: 167) adalah hitam, merah, kuning kejinggaan, merah, dan warna emas. Warna pelengkapnya antara lain biru, merah jambu, ungu, merah tua, dan hijau muda. Bila ditemukan warna yang sifatnya analog atau nada warna, maka hal itu terjadi karena pengaruh dari luar.

\section{E-book}

Seiring dengan perkembangan zaman buku tidak hanya berbentuk fisik saja, namun kini buku sudah berbentuk digital (e-book). Saat ini masyarakat lebih menginginkan hal yang praktis seperti e-book yang mudah didapatkan dibandingkan buku konvensional yang membutuhkan berhari-hari untuk mendapatkannya.

Menurut Wiji Suwarno (2011: 74), e-book adalah versi elektronik dari buku. Sebuah bentuk buku yang dapat dibuka secara elektronis melalui komputer maupun smartphone. Bedasarkan pengertian tersebut, dapat dilihat bahwa Electronic Book (e-book) merupakan suatu terobosan baru dalam ruang lingkup media bacaan, dimana buku dapat dibaca dan diakses melalui internet.

Berdasarkan pembahasan mengenai e-book diatas dapat disimpulkan bahwa e-book merupakan buku digital yang didapatkan melalui internet. Kecepatan internet yang meningkat, menghasilkan penyebaran $e$ book melalui jalur yang cepat pula. Nantinya ilustrasi cerita rakyat Anggun Nan Tongga akan diaplikasikan menjadi e-book yang dapat dibaca melalui berbagai perangkat komputer maupun smartphone dengan akses internet. Perancangan ilustrasi ini menggunakan format $J P E G$ dengan tampilan buku.

\section{METODE PENELITIAN}

Perancangan ini dilakukan menggunakan metode penelitian kualitatif, dengan teknik pengumpulan data studi pustaka, observasi, wawancara, dan data visual. Observasi dilakukan ke tempat-tempat yang diperlukan seperti perpustakaan yang memiliki
Gorga Jurnal Seni Rupa

Volume 08 Nomor 01 Januari-Juni 2019

p-ISSN: 2301-5942 | e-ISSN: 2580-2380

informasi mengenai artevak visual adat dan budaya Pariaman seperti di Pusat Dokumentasi dan Informasi Padangpanjang dan Museum Adityawarman untuk di visualisasi dalam perancangan ilustrasi cerita rakyat Anggun Nan Tongga. Serta melakukan observasi langsung ke Pariaman untuk mempelajari latar tempat.

Wawancara yang telah dilakukan kepada ibu Zurneli Zubir, peneliti Balai Pelestarian Nilai Budaya Sumatera Barat. Beliau menyatakan mengenai pakaian masyarakat Pariaman pada abad $16 \mathrm{M}$, pria menggunakan Baju Teluk Belango dengan bawahan berkain sarung, sedangkan wanita Menggunakan Baju Kuruang. Selain pakaian juga ditanyakan mengenai arsitektur rumah masyarakat Pariaman dahulunya. Rumah khas di Pariaman merupakan tipe Rumah Gadang Tungkuik Nasi dan memiliki pengaruh arsitektur Aceh. Bentuk atap ini disesuaikan dengan kondisi cuaca di daerah pesisir yang cenderung berangin kencang.
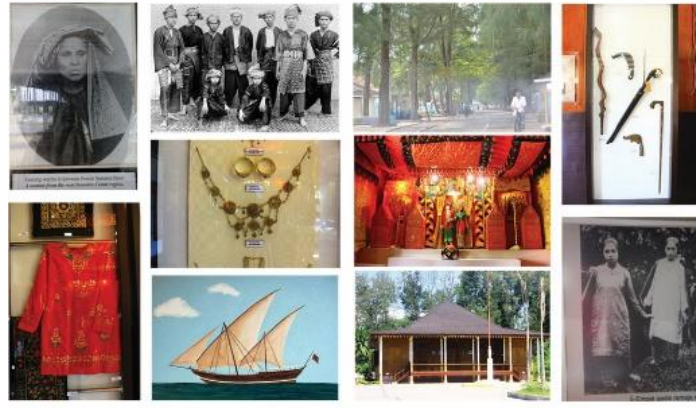

Gambar 1. Data Visual

(Sumber: Assaidatull Husna, 2018)

Metode analisis data yang digunakan dalam pemecahan masalah ini adalah dengan menggunakan analisis SWOT (Strenght, Weakness, Opportunity, Threat). Analisis SWOT digunakan untuk menentukan konsep dalam perancangan, yaitu dengan mengkaji gagasan yang akan dinilai dengan cara memilah dan menginventarisasi kekuatan kelemahan, ancaman, dan peluang dari objek perancangan. Berikut adalah analisis data dari perancangan ilustrasi cerita rakyat Anggun Nan Tongga:

1. Strength

A. Cerita rakyat Anggun Nan Tongga memiliki nilai budaya dan nilai moral masyarakat Pariaman.

B. Cerita rakyat Anggun Nan Tongga merupakan karya sastra dari Pariaman yang melegenda.

2. Weakness

A. Tidak adanya sosialisasi yang efektif oleh pemerintah terhadap cerita rakyat Anggun Nan Tongga kepada masyarakat terutama remaja.

B. Tidak ada penerus cerita rakyat Anggun Nan Tongga selain sesepuh masyarakat.

3. Opportunity

A. Memperkenalkan nilai-nilai moral dan budaya masyarakat Pariaman secara luas. 


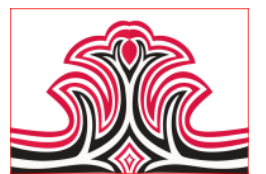

B. Cerita rakyat Anggun Nan Tongga akan menjadi dokumentasi dan arsip pemerintah Pariaman.

4. Threat

A. Cerita rakyat Anggun Nan Tongga ini akan hilang ditelan oleh zaman.

B. Cerita rakyat dengan nilai budaya dan moral akan hilang, sehingga generasi muda akan kehilangan karakter budayanya.

C. Cerita rakyat nusantara kurang popular dibandingkan cerita luar negeri.

\section{HASIL DAN PEMBAHASAN}

\section{Hasil}

\section{1).Sinopsis Cerita}

Tabel 1. Storyline Cerita Rakyat Anggun Nan Tongga

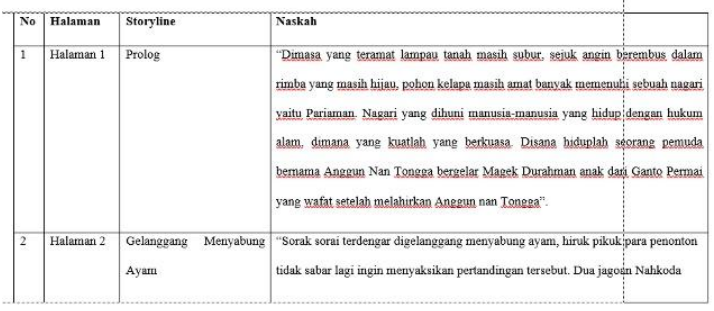

\section{(1).Desain Karakter}

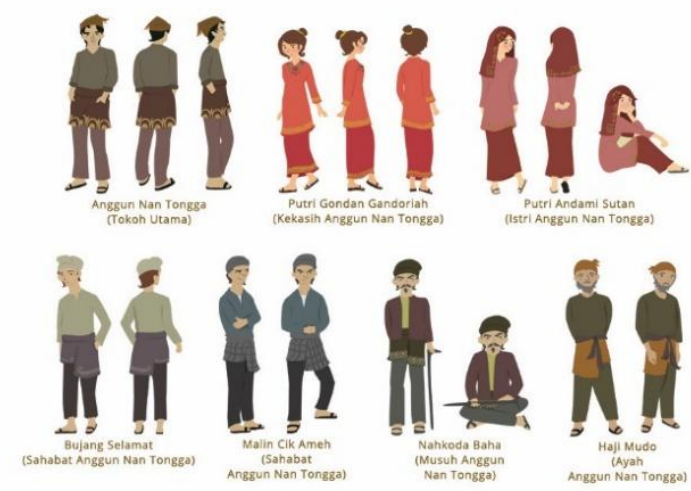

Gambar 2. Karakter Cerita Rakyat Anggun Nan Tongga (Sumber: Assaidatul Husna, 2018)

\section{2).Storyboard}

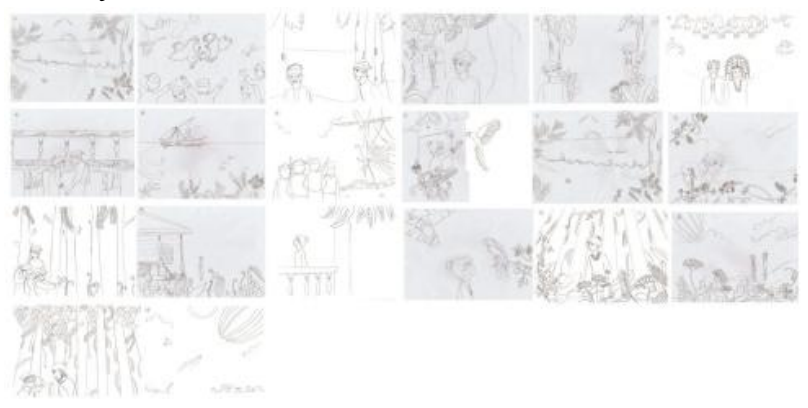

Gambar 3. Storyboard Cerita Rakyat Anggun Nan Tongga (Sumber: Assaidatul Husna, 2018)

\section{3).Final Desain}

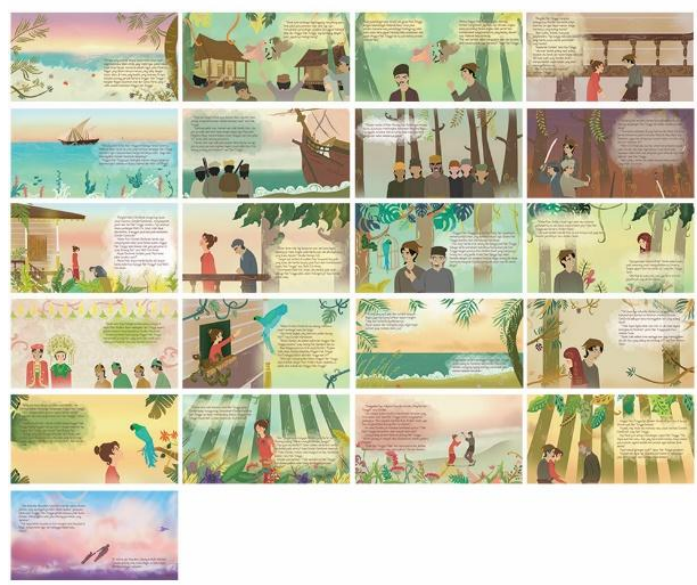

Gambar 4. Final Desain Cerita Rakyat Anggun Nan Tongga (Sumber: Assaidatul Husna, 2018)

\section{4).Pengaplikasian pada Media E-book}

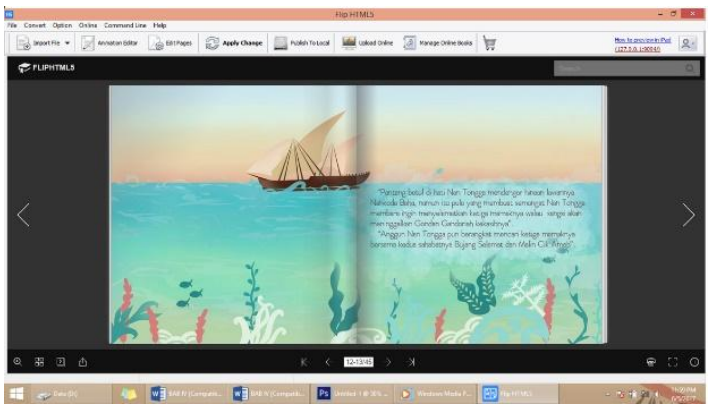

Gambar 5. Pengaplikasian Halaman 5

(Sumber: Assaidatul Husna, 2018)

\section{Pembahasan}

\section{1).Ruang Lingkup Perancangan}

Demografi, perancangan ini ditargetkan untuk generasi muda yang dikhususkan pada: usia: 13-18 tahun yang terdiri dari remaja awal dan remaja akhir dengan pendidikan SMP dan SMA, di mana alur cerita rakyat Anggun Nan Tongga dapat dijangkau oleh usia remaja. Kehidupan cerita yang berkorelasi dengan dunia remaja dan bahasa yang digunakan sesuai dengan perkembangan dan emosional usia tersebut. Sehingga nilai budaya dan moral yang terkandung di dalam cerita rakyat Anggun Nan Tongga dapat dipahami. 2) Geografi, wilayah sasaran yang dituju adalah masyarakat Pariaman Sumatera Barat, masyarakat Pariaman yang berada di daerah rantau dan tidak menutup kemungkinan masyarakat luas. 3) Psikografis, perancangan ilustrasi cerita rakyat ini ditujukan kepada generasi muda yang mengikuti perkembangan zaman dan tidak suka membaca text book yang panjang. 


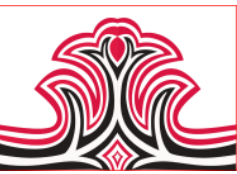

2).Konsep Kreatif

Kurangnya ketertarikan masyarakat terutama generasi muda terhadap text book cerita rakyat Anggun Nan Tongga, maka diperlukan media komunikasi visual yang efektif, media yang dapat menarik perhatian dan mengikuti perkembangan zaman. Sehingga generasi muda akan membaca cerita rakyat ini. Salah satu ide gagasannya yaitu perancangan ilustrasi yang diaplikasikan melalui media $e$-book.

\section{(1).Konsep Visual}

\section{a.Ilustrasi}

Eksplorasi, pada tahapan awal proses perancangan ilustrasi ini, yaitu mencari referensi berupa kebudayaan dan alam Pariaman. Kebudayaan Pariaman berupa rumah masyarakat Pariaman, pakaian, senjata, transportasi, serta beberapa foto masyarakat dahulu sebagai referensi perancangan. Sedangkan alam Pariaman diperoleh dari observasi dan foto yang terdapat di Pariaman seperti pantai, pohon-pohon pinus dan hutan. Improvisasi, setelah melakukan pencarian data yang dibutuhkan dalam perancangan selanjutnya membuat sketsa-sketsa yang dibuat menjadi bentuk lebih sederhana dan mengeksplorasikannya dengan cara baru seperti perancangan ide tumbuhan-tumbuhan yang ada di hutan dirancang dekoratif sehingga menambah nilai estetik dari perancangan. Hal inilah yang dipakai sebagai pedoman dalam merealisasikan wujud dari gagasan perancangan. Perwujudan, tahap pembentukan sketsa-sketsa terpilih, dilakukannya proses kreatif berupa pewarnaan, layout, dan tipografi. Pemilihan warna pada ilustrasi disesuaikan dengan warna asli objek namun lebih lembut dengan tujuan mengikuti konsep.

\section{b.Tipografi}

Dalam perancangan Anggun Nan Tongga, jenis-jenis tipografi yang digunakan adalah jenis tipografi yang mewakili bentuk ilustrasi dan jenis cerita tersebut. Tipografi headline yaitu Banana Yeti dan bodytext menggunakan Amsdam dimana kedua tipografi ini menghasilkan efek yang diinginkan yaitu bentuk dinamis dan dekoratif. Kedua jenis font ini akan menyampaikan informasi dan pesan yang baik.

\section{c.Warna}

Warna yang akan digunakan pada media utama adalah full color. Warna yang dihadirkan berupa warnawarna yang lebih lembut dari warna asli objek yang akan diilustrasikan. Pewarnaan ilustrasi dilakukan dengan software grafis (Adobe Photoshop CS6) dengan teknik block dan digital painting yang tidak dominan.
Gorga Jurnal Seni Rupa

Volume 08 Nomor 01 Januari-Juni 2019

p-ISSN: 2301-5942 | e-ISSN: 2580-2380

\section{d.Layout}

Layout pada ilustrasi Anggun Nan Tongga disusun sedemikian rupa sehingga membentuk kesatuan antara elemen teks dan elemen visual yang terdapat pada ilustrasi ini. Selanjutnya layout yang konsisten sehingga membentuk pola yang harmonis.

\section{e.Bentuk}

Bentuk digital yang dipilih dalam perancangan ilustrasi Anggun Nan Tongga adalah tampilan majalah digital. Pemilihan tampilan ini tentunya disesuaikan dengan target audience yang dekat dengan penggunaan internet.

\section{3).Strategi Kreatif}

Strategi perancangan ilustrasi cerita rakyat Anggun Nan Tongga akan di setting pada abad ke $16 \mathrm{M}$, dimana menampilkan suasana pada saat Islam baru masuk ke Pariaman. Di masa ini masyarakat masih menggunakan baju teluk belango bagi pria sedangkan baju kuruang bagi wanita. Selain itu masyarakat tinggal di rumah gadang kajang padati dan tungkuik nasi.

Dalam perancangan ilustrasi Anggun Nan Tongga menampilkan ilustrasi dan teks yang tidak dominan. Teknik ilustrasi yang ditampilkan adalah ilustrasi digital block yang dirancang dekoratif sehingga menambah nilai estetik dari perancangan. Warna yang dihadirkan berupa warna-warna yang lebih lembut dari warna asli objek, dengan tujuan mengikuti selera masyarakat/selera pasar saat ini. Teks dari cerita rakyat ini akan diedit menjadi lebih sederhana dan singkat tanpa menghilangkan intisari dari cerita rakyat Anggun Nan Tongga.

Cerita rakyat Anggun Nan Tongga akan ditampilkan dalam bentuk $e$-book berupa majalah digital yang tiap lembarnya akan menampilkan ilustrasi beserta teks. Menggunakan $e$-book sebagai media penyampai cerita rakyat Anggun Nan Tongga dikarenakan generasi muda sekarang sangat dekat dengan penggunaan gadget seperti smartphone dan computer. Website ebook ilustrasi Anggun Nan Tongga yang digunakan dapat diakses oleh seluruh jenis smartphone maupun komputer. Selanjutnya $e$-book cerita rakyat Anggun Nan Tongga akan disebarkan melalui Instagram sebagai strategi promosi, sosial media ini dapat mengkategorikan jenis postingan sehingga lebih mudah menemukan postingan yang diunggah. 


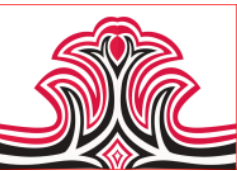

\section{KESIMPULA DAN SARAN}

\section{Kesimpulan}

Upaya dalam dokumentasi cerita rakyat tersebut sudah dilakukan oleh beberapa penerbit di Sumatera Barat berupa text book. Minat membaca masyarakat yang kurang, menyebabkan diperlukannya sebuah media komunikasi visual yang efektif dalam mendokumentasikan dan melestarikan cerita rakyat Anggun Nan Tongga ini.

Maka dirancanglah ilustrasi cerita rakyat Anggun Nan Tongga melalui media e-book dengan tujuan dapat menarik minat remaja untuk membaca cerita rakyat ini. Pemilihan $e$-book atas dasar remaja saat ini dekat dengan penggunaan internet.

Perancangan ini diawali dengan mencari referensi terkait berupa kebudayaan dan alam Pariaman, selanjutnya membuat sketsa-sketsa, pemilihan warna, pemilihan tipografi dan penyusunan layout yang disesuaikan dengan konsep. Kemudian ilustrasi ini akan diaplikasikan ke e-book dengan tampilan majalah.

\section{Saran}

Berdasarkan perancangan ini terdapat beberapa saran yang dapat diberikan untuk berkembangnya kreatifitas dalam karya sejenis, diantaranya: A) Dalam perancangan ilustrasi cerita rakyat banyak hal yang harus diperhatikan secara mendetail, seperti melakukan observasi dan mencari informasi yang mendukung perancangan. B) Dalam pengembangan media ini untuk berikutnya dapat menerjemahkannya kedalam bahasa asing sehingga cerita rakyat dapat dikenal masyarakat luas dan dapat bersaing dengan buku dongeng luar negeri. C) Dalam pengembangan media ini nantinya diharapkan tampilan visual diperhatikan karena unsur visual mewakili identitas dari objek perancangan kepada target audience. D) Harapan dari media ini dapat ditanggapi oleh pemerintah Pariaman sehingga dapat dipaten dan diterbitkan.

\section{DAFTAR RUJUKAN}

Darmaprawira, WA Sulasmi. (2002. Warna Teori dan Kreatifitas Penggunaannya. Bandung: Penerbit ITB.

Navis, A.a. (1983). Warna Lokal Minangkabau dalam Sastra Indonesia Mutakhir" dalam Horison, Th. XXVIII. Jakarta:

Krause, Jim. (2002). Colour Index. United Kingdom: David and Charles Press.

Kusrianto, Adi. (2009). Pengantar Desain Komunikasi Visual. Yogyakarta: Andi Press.
Gorga Jurnal Seni Rupa

Volume 08 Nomor 01 Januari-Juni 2019

p-ISSN: 2301-5942 | e-ISSN: 2580-2380

Rustan, Surianto. (2009). Layout Dasar Dan Penerapannya. Jakarta: Gramedia Pustaka Utama.

(2010). Hurufontipografi. Jakarta: Gramedia Pustaka Utama.

Suwarno, Wiji. (2011). Perpustakaan dan Buku: Wacana Penulisan dan Penerbitan. Yogyakarta: Ar-Ruzz Media.

Wallschlaeger, Charles and Busic-Snyder, Chyntia. (1992). Bacic Visual Concepts and Principles. USA: Brown \& Benchmark (MHR).

Wojirsch. (1995). Pengertian Ilustrasi. Diunduhpada 23 Juni 2017. [Online]. Di http://www.ejurnal.com/2013/04/pengertian -ilustrasi.html. 